\title{
Assessment of Hepatitis B Virus Screening Behaviors among Asian-Americans through the Lens of Social Cognitive Theory
}

\author{
Daisy Le ${ }^{1} \oplus$, Alicia Hong $\oplus$, Siu-Kuen Azor Hui ${ }^{3} \oplus$, Rajiv N Rimal ${ }^{4} \oplus$, and Hee-Soon Juon ${ }^{5}$ \\ ${ }^{1}$ George Washington University \\ ${ }^{2}$ George Mason University \\ ${ }^{3}$ Dr. Hui Consulting, \\ ${ }^{4}$ Johns Hopkins Bloomberg School of Public Health \\ ${ }^{5}$ Thomas Jefferson University
}

\begin{abstract}
Background and Purpose: Asian-Americans suffer from significant liver cancer disparity caused by chronic hepatitis B virus (HBV) infection. Understanding psychosocial predictors of HBV screening is critical to designing effective interventions. Methods: Chinese-, Korean-, and Vietnamese-Americans in the Baltimore-Washington metropolitan region $(\mathrm{N}=877)$ were recruited from community-based organizations. Applying the Social Cognitive Theory (SCT), three main theoretical constructs (knowledge, outcome expectancy, and self-efficacy) were tested. Descriptive analyses using Chi-square and ANOVA and multivariate logistic regression models were conducted. Results: About 47\% of participants reported ever having screening for HBV. Vietnamese-Americans had the lowest HBV screening rate (39\%), followed by Korean-Americans (46\%) and Chinese-Americans (55\%). Multiple logistic regression analyses showed significant effects of HBV-related knowledge on screening in all three groups, whereas selfefficacy had significant effects in the Chinese and Korean subgroups, but not Vietnamese. HBV outcome expectancy had no effect on the screening outcome in any of the groups. Additionally, consistent in all three groups, those who had lived in the United States longer were less likely to have screening. Conclusion: HBV screening rates in Asian Americans remain low; targeted interventions need to consider the differences across ethnic subgroups and address the psychosocial risk factors.
\end{abstract}

(C) 2021 and CC-BY 4.0 licensed by the authors.

Keywords: Hepatitis B virus infection, Hepatitis B virus screening, Social Cognitive Theory, Self-efficacy, Asian American Health

\section{Introduction}

Asian-Americans (AAs) have the highest liver cancer mortality rates of all racial/ethnic groups, with Vietnamese-American (VA) men having the highest rates $(26.2 / 100,000)$, followed by Korean-American (KA) men $(18.2 / 100,000)$ and Chinese-American (CA) men $(14.5 / 100,000)$ (Thompson et al., 2016). Liver cancer associated with chronic hepatitis B virus (HBV) in AAs is one of the most serious, but frequently neglected, racial/ethnic disparities in the United States (US) (US Department of Health and Human Services
Office of HIV/AIDS and Infectious Disease Policy, 2017). While the AA population is a very heterogeneous group of individuals with origins in the Far East, Southeast Asia, or the Indian subcontinent (Kagawa-Singer \& Kho, 2015), available health statistics on AAs are often presented in aggregate (Chen \& Dang, 2015). However, by disaggregating by ethnicity and gender, VA men for example, have a noticeably higher HBV positivity rate when compared to the general AA population $(13.6 \%$ and about $10 \%$, respectively) (Chen \& Dang, 2015; Ma et al., 2011). Stark and alarming differences between 
AA subpopulations, such as the aforementioned, further contribute to the devastating disparities in cancer outcomes for and within the AA community (Chen \& Dang, 2015).

Because of the asymptomatic nature of chronic HBV, about $65 \%$ of infected adults are unaware of their condition (Institute of Medicine [IOM], 2010). Of 53,896 respondents to the Racial and Ethnic Approaches to Community Health $(\mathrm{REACH})$ survey that represented diverse racial/ethnic backgrounds across the US, only $39.2 \%$ had ever been HBV screened (Hu et al., 2013; Ma et al., 2017). Studies of AA populations, in particular, have also shown low self-reported HBV screening rates which range widely from $7.5 \%$ to $43 \%$ by various Asian ethnic groups and geographical regions (Juon, Rimal, Klassen, \& Lee, 2017; Ma et al., 2017; Thompson et al., 2016; Strong, Lee, Tanaka, \& Juon, 2012). In a survey of 1,312 AAs from the greater Philadelphia area, New Jersey, and New York City, Ma and colleagues (Ma et al., 2011; Juon et al., 2017) found significant ethnic differences in HBV screening: VA $(20.3 \%)$ had the lowest screening rate, followed by KA $(32.2 \%)$ and CA $(37.9 \%)$.

As HBV screening is the first step in liver cancer prevention; understanding its psychosocial determinants is crucial for designing targeted interventions for this rapidly growing and highrisk racial/ethnic community. The Social Cognitive Theory (SCT) is a widely-studied health psychology theory (Bandura, 1998), yet studies strictly applying it to examine HBV screening behavior specifically among, and across, higher-risk AA subpopulations remains largely limited (Lee et al., 2017; Ma et al., 2017). Accordingly, we applied the SCT to understand the psychosocial determinants of HBV screening using baseline survey data collected by the Maryland Asian American Liver Cancer Education Program (see more detail, Juon et al., 2014, Strong et al., 2012). The SCT postulates that health-promoting behaviors are more likely to occur if an individual has increased any of the three main theoretical constructs (knowledge, outcome expectancy, and self-efficacy). We hypothesized that HBV screening in AAs remains low and that HBV knowledge, self-efficacy of HBV screening, and outcome expectancy are positively and independently associated with HBV screening.

\section{Methods}

\section{Study Design and Sample}

We drew data from the baseline survey collected for the Maryland Asian American Liver Cancer Education Program (hereinafter referred to as "the Program"). The Program was a cluster randomized controlled intervention trial that tested a HBV and liver cancer educational program. Approval for Human Subject Research was obtained from the Institutional Review Board of the Johns Hopkins Bloomberg School of Public Health.

Of a total of 940 recruited individuals who selfidentified as AA adults (18 years of age and older), $93 \%(n=877)$ completed the paper-based, self-administered questionnaire. This sample included $303 \mathrm{CA}, 294 \mathrm{KA}$, and $280 \mathrm{VA}$ recruited through various faith-based (churches and temples) and community-based organizations (language schools and college cultural student groups) from the Baltimore-Washington metropolitan region, as well as from Asian grocery stores, restaurants, and nail salons. Individual networks, specific to each subpopulation, included: churches and language schools for CA; churches, grocery stores, and restaurants for $\mathrm{KA}$; and churches, temples, restaurants, and nail salons for VA. Sampling frame for these organizations was created from ethnic yellow-pages, industry membership directories, and suggestions from community leaders. A total of 32 organizations agreed to participate in the Program. Organizational membership, however, was not required for participation (for more details, see Juon \& Park, 2013 and Strong, Lee, Tanaka, \& Juon, 2012). Of 
the 877 respondents, the average age was 45.1 years and $41.5 \%$ were males; $13.2 \%$ had less than a high school education and $14.4 \%$ had a family history of HBV infection. About 38\% of respondents reported being recent immigrants (i.e., US resident for $<25 \%$ of their lifetime).

\section{Measures}

In their preferred language (their native language or English), study participants completed a survey on their HBV screening behavior, psychosocial characteristics, and demographics. $H B V$ screening behavior, the dependent variable, was measured by asking participants "Have you ever had HBV screening?" ( $0=$ no; 1=yes) (Strong et al., 2012). Self-efficacy measured the level of self-confidence for screening uptake under challenging circumstances (Lee et al., 2017) (e.g., I am confident that I can make an appointment to get HBV tested and keep that appointment) $(n=4$; $\alpha=0.90$ ). This was measured on a 7-point Likert scale from "strongly agree" (7) to "strongly disagree" (1). A composite index score was created by calculating a summative mean with higher score indicating a higher level of selfefficacy. The mean of composite measure was 19.9 (6.3SD, 4-28 range).

Outcome expectancy measured participants' perceived consequences of HBV infection (e.g., People with HBV are infected for life) ( $\mathrm{n}=7$, $\alpha=0.78$ ). Each correct answer was given one point and a summative score was calculated (Juon \& Park, 2013). The mean of composite measure of outcome expectancy was 3.9 (2.1SD, 0-7 range). $H B V$ knowledge on transmission was also measured (e.g., mother-to-child) $(\mathrm{n}=10 ; \alpha=0.81)$. Each correct answer was given one point and a summative score was calculated (Juon \& Park, 2013). The mean of composite measure of knowledge was 4.6 (2.5SD, 0-10 range). Demographic variables included age, sex, education level, and family history of HBV infection $(0=$ no/not sure; $1=y e s)$. As a proxy measure for acculturation, the proportion of life in the US was calculated by dividing the number of years living in the US by current age and was used as a dichotomous variable $(0=<25 \% ; 1=$ $\geq 25 \%$ ) (Juon et al., 2017; Tanaka, Strong, Lee, \& Juon, 2013).

\section{Statistical Analyses}

We first examined the frequencies of key variables, including demographic characteristics, SCT constructs, and HBV screening by ethnicity. We also compared differences between the three ethnicities using Chi-square or ANOVA. Multivariate logistic regression was conducted to investigate the effects of SCT on HBV screening behavior while controlling for potential confounders. Analyses were performed using Stata 15.1 (StataCorp, 2019).

\section{Results}

Table 1 presents participants' key characteristics by ethnicity. There were ethnic differences in age, education, and proportion of life spent in the US. CA participants had highest rate of education: about half had more than graduate school education, followed by KA $(17.3 \%)$ and VA $(8.2 \%)(p<.001)$. VA participants $(69.2 \%)$ had higher rate of spending more than $25 \%$ of life spent in the US than KA (59.5\%) and CA (58.1\%) $(\mathrm{p}<.05)$. CA participants had higher mean scores of knowledge of $\mathrm{HBV}$ transmission and expectancy outcome than KA and VA. VA (22.1) had highest mean scores of self-efficacy, followed by KA (19.5) and CA (18.5) $(\mathrm{p}<.001)$. For the HBV screening, VA had the lowest screening rate $(39.4 \%)$, followed by KA $(45.6 \%)$ and CA $(54.6 \%)(\mathrm{p}<.001)$.

Table 2 shows results of multivariate logistic regressions on the psychosocial factors associated with HBV screening by subgroups of AAs. Self-efficacy was associated with HBV screening in $\mathrm{CA}(\mathrm{aOR}=1.07,95 \% \mathrm{CI}=1.02-1.11)$ and $\mathrm{KA}(\mathrm{aOR}=1.08,95 \% \mathrm{CI}=1.03-1.13)$. HBV knowledge was associated with HBV screening among $\mathrm{CA}(\mathrm{aOR}=1.18,95 \% \mathrm{CI}=1.04-1.34)$ and VA $(\mathrm{aOR}=1.12,95 \% \mathrm{CI}=1.01-1.25)$. Outcome expectancy was not significant in any group. 
Table 1.

Key Characteristics of Participants Comparing Three Ethnic Groups

\begin{tabular}{|c|c|c|c|c|}
\hline & Chinese-Americans & Korean-Americans & $\begin{array}{r}\text { Vietnamese- } \\
\text { Americans } \\
\end{array}$ & p-value \\
\hline \multirow{2}{*}{ Characteristic } & $(n=303)$ & $(n=294)$ & $(n=280)$ & \\
\hline & $\mathrm{N}(\%)$ & $\mathrm{N}(\%)$ & $\mathrm{N}(\%)$ & \\
\hline Age (mean $\pm S D$, range) & $\begin{array}{r}45.9 \pm 11.5 \\
(21-80)\end{array}$ & $\begin{array}{r}46.1 \pm 13.5 \\
(19-77)\end{array}$ & $\begin{array}{r}43.1 \pm 15.1 \\
(18-89)\end{array}$ & 0.013 \\
\hline \multicolumn{5}{|l|}{ Gender } \\
\hline Male & $120(39.6)$ & $113(38.4)$ & $131(46.8)$ & 0.09 \\
\hline Female & $183(60.4)$ & $181(61.6)$ & $149(53.2)$ & \\
\hline \multicolumn{5}{|l|}{ Education } \\
\hline$<$ High school & $23(7.6)$ & $38(12.9)$ & $55(19.6)$ & $<.001$ \\
\hline High school+ & $48(15.8)$ & $109(37.1)$ & $138(49.3)$ & \\
\hline College graduate & $80(26.4)$ & $96(32.7)$ & $64(22.9)$ & \\
\hline Graduate school+ & $152(50.2)$ & $51(17.3)$ & $23(8.2)$ & \\
\hline \multicolumn{5}{|l|}{ Has HBV infected family } \\
\hline No/not sure & $260(85.8)$ & $255(87.0)^{\mathrm{a}}$ & $233(83.8)^{b}$ & 0.544 \\
\hline Yes & $43(14.2)$ & $38(13.0)$ & $45(16.2)$ & \\
\hline \multicolumn{5}{|c|}{ Proportion of life spent in U.S. } \\
\hline$<25 \%$ in life & $127(41.9)$ & $119(40.5)$ & $86(30.8)^{\mathrm{a}}$ & 0.012 \\
\hline$\geq 25 \%$ in life & $176(58.1)$ & $175(59.5)$ & $193(69.2)$ & \\
\hline $\begin{array}{l}\text { Knowledge of transmission } \\
(0-10)(\text { mean } \pm S D)\end{array}$ & $4.9 \pm 2.4$ & $4.1 \pm 2.3$ & $4.6 \pm 2.7$ & $<.001$ \\
\hline $\begin{array}{l}\text { Outcome expectancy } \\
(0-7)(\text { mean } \pm S D)\end{array}$ & $4.4 \pm 1.9$ & $3.4 \pm 1.9$ & $3.9 \pm 2.2$ & $<.001$ \\
\hline $\begin{array}{l}\text { Self-efficacy } \\
\quad(4-28)(\text { mean } \pm S D)\end{array}$ & $18.5 \pm 6.5$ & $19.5 \pm 5.9$ & $22.1 \pm 6.1$ & $<.001$ \\
\hline \multicolumn{5}{|l|}{ HBV screening } \\
\hline No & $137(45.4)$ & $160(54.4)$ & $169(60.6)$ & $<.001$ \\
\hline Yes & $165(54.6)$ & $134(45.6)$ & $110(39.4)$ & \\
\hline
\end{tabular}

Note. ${ }^{\mathrm{a}} 1$ did not respond; ${ }^{\mathrm{b}} 2$ did not respond

Table 2.

Multivariate Logistic Regression of HBV Screening on Psychosocial Factors, by Ethnicity

\begin{tabular}{|c|c|c|c|}
\hline & $\begin{array}{r}\text { Chinese } \\
(\mathrm{n}=\mathbf{3 0 3}) \\
\text { OR }(\mathbf{9 5 \%} \mathrm{CI}) \\
\end{array}$ & $\begin{array}{r}\text { Korean } \\
(\mathrm{n}=294) \\
\text { OR }(\mathbf{9 5 \%} \mathrm{CI}) \\
\end{array}$ & $\begin{array}{r}\text { Vietnamese } \\
(n=280) \\
\text { OR }(95 \% \mathrm{CI})\end{array}$ \\
\hline Age & $0.99(0.97-1.02)$ & $1.03(1.01-1.05)^{*}$ & $1.01(0.99-1.03)$ \\
\hline Gender $(\operatorname{Ref}=$ male $)$ & $0.84(0.50-1.41)$ & $0.59(0.35-1.01)$ & $0.97(0.57-1.66)$ \\
\hline \multicolumn{4}{|l|}{ Education $(\operatorname{Ref}=<$ high school $)$} \\
\hline High school graduate & $2.18(0.58-8.14)$ & $1.25(.0 .52-3.02)$ & $1.86(0.84-4.09)$ \\
\hline$\geq$ College education & $4.40(1.31-14.76)^{*}$ & $1.80(0.72-4.42)$ & $2.89(1.15-7.24)^{*}$ \\
\hline $\begin{array}{l}\text { Proportion of life living in U.S. (Ref } \\
=<25 \%)\end{array}$ & $0.57(0.33-0.97)^{*}$ & $0.35(0.20-0.61)^{*}$ & $0.50(0.28-0.91)^{*}$ \\
\hline $\begin{array}{l}\text { Family having HBV infection (Ref } \\
=n o)\end{array}$ & $2.02(0.91-4.50)$ & $1.42(0.66-3.05)$ & $2.44(1.18-5.03)^{*}$ \\
\hline HBV knowledge & $1.18(1.04-1.34)^{*}$ & $1.13(0.99-1.28)$ & $1.12(1.01-1.25)^{*}$ \\
\hline Self-efficacy & $1.07(1.02-1.11)^{*}$ & $1.08(1.03-1.13)^{*}$ & $1.01(0.97-1.06)$ \\
\hline Outcome expectancy & $1.11(0.96,1.29)$ & $1.13(0.97-1.31)$ & $1.02(0.89-1.16)$ \\
\hline
\end{tabular}

Note. ${ }^{*} \mathrm{p}<.05$ 
Across ethnicities, acculturation was associated with screening in all three groups (aOR ranged 0.20 to 0.57 ): Those more acculturated were less likely to have screening than those less acculturated (e.g., recent immigrants). Education was significantly associated with screening in CA and VA: Those with more than college education reported higher screening than those less than high school education in $\mathrm{CA}(\mathrm{aOR}=4.40,95 \%$ $\mathrm{CI}=1.31-14.76)$ and $\mathrm{VA} \quad(\mathrm{aOR}=2.89,95 \%$ $\mathrm{CI}=1.15-7.24)$. Family history of HBV infection was related with screening for VA only $(\mathrm{aOR}=2.44,95 \% \mathrm{CI}=1.18-5.03)$.

\section{Discussion}

As one of the few current studies that directly applies the SCT constructs to understand HBV screening behavior among AA subpopulations, it is also one of the first efforts that compared the psychosocial factors of HBV screening across three higher-risk AA ethnic subgroups in one study. Knowledge was a significant factor among $\mathrm{CA}$ and VA, but outcome expectancy was not. Additionally, self-efficacy was significant only among $\mathrm{CA}$ and KA, but not VA. College education, family history of HBV infection, and recent US immigration were also significant factors associated with HBV screening.

HBV prevalence in the general US population remains low (0.35\%) (Le et al., 2020; Chen \& Dang, 2015); most US-born individuals have received $\mathrm{HBV}$ vaccines at infancy and therefore HBV screening in the general population is suboptimal (CDC, 2005). In contrast, the prevalence of $\mathrm{HBV}$ infection is higher among AA than any other racial/ethnic groups in the US (Chen \& Dang, 2015). While AAs make up only about $5 \%$ of the US population, they account for more than $50 \%$ of all Americans with chronic HBV (Chen \& Dang, 2015) and consist of racial/ethnic subgroups that have some of the lowest self-reported HBV screening rates in the US. Furthermore, as many AAs are firstgeneration immigrants from chronic $\mathrm{HBV}$ endemic regions, most have limited knowledge of the virus and are unaware of their risks (IOM, 2010; Juon et al., 2017). Because of poor HBV knowledge, they may not have a good understanding of the true sequela of HBV infection. This may explain that outcome expectancy was not significantly associated with HBV screening.

Our findings underscored the importance of targeted interventions that enhance HBV knowledge and self-efficacy in screening to promote HBV screening behavior. Such interventions are particularly necessary among groups with lower-levels of education and those more acculturated. Our findings that AAs living in the US longer were less likely to have HBV screening are consistent with other AA studies (Strong et al., 2012; Tanaka et al., 2013). This may be due to lower perceived risk of HBV infection as one becomes more identified as an American, since an average American has lower risk of HBV infection than an average Asian (Juon et al., 2017). The disaggregating of data by ethnicity suggest that HBV prevention and control efforts and culturally-appropriate interventions could be more precisely targeted and tailored to the subgroup differences that were found across the 3 ethnic subpopulations.

In recent years, some interventions have been implemented to improve HBV knowledge in AAs (Juon \& Park, 2013; Ma et al., 2017). These programs, though culturally-tailored and linguistically-appropriate, have not targeted the differences across ethnic subgroups. AAs represent diverse groups coming from countries of different political systems, religions, languages, and immigration histories; these differences are also exhibited in their health behaviors and associated psychosocial factors. Research and practice promoting HBV screening in AAs that integrate behavioral theories into evidence-based community interventions are vital to the effective reduction of liver cancer disparities (Bastani et al., 2010). 


\section{Limitations}

First, participants were recruited through AA community-based organizations from the Baltimore-Washington region; they may not represent AAs across the country. Second, we only included the major SCT constructs and key demographics in measurement of psychosocial factors of HBV screening; other important factors (e.g., provider's recommendation; social support; family communication; social norms) might have been missed. Third, the study was based on a cross-sectional survey; the associations we observed could not be interpreted as causal relationships. For example, it is possible that (1) participants who have been previously screened for HBV are more self-confident about screening and/or (2) those who have previously tested positive have more HBV knowledge given their disease status. Longitudinal studies are needed to identify the causing psychosocial factors of HBV screening.

\section{Conclusions}

Guided by the SCT, we learned that HBV-related knowledge and self-efficacy are significantly associated with HBV screening behavior among AAs. Culturally-appropriate and ethnic-specific interventions are needed to especially reach AAs with lower-levels of education, as well as those who have lived in the US longer. Given that several studies have reported that AAs have low self-reported HBV screening rates (Juon et al., 2017; Ma et al., 2017; Thompson et al., 2016; Strong et al., 2012), theory-guided interventions that address the above-mentioned psychosocial factors are critical to address the significant liver cancer disparities in AAs.

\section{References}

Bandura, A. (1998). Health promotion from the perspective of social cognitive theory. Psychology and Health, 13, 623-649. doi: 10.1080/08870449808407422

Bastani, R., Glenn, B. A., Taylor, V. M., Chen, M. S., Jr, Nguyen, T. T., Stewart, S. L., \& Maxwell, A. E. (2010). Integrating theory into community interventions to reduce liver cancer disparities: The health behavior framework. Preventive Medicine, 50(1-2), 63-67. doi:10.1016/j.ypmed.2009.08.010

Chen Jr, M. S., \& Dang, J. (2015). Hepatitis B among Asian Americans: Prevalence, progress, and prospects for control. World Journal of Gastroenterology, 21(42), 11924. doi: 10.3748/wjg.v21.i42.11924

Centers for Disease Control and Prevention. (2005). A comprehensive immunization strategy to eliminate transmission of hepatitis B virus infection in the United States: Recommendations of the Advisory Committee on Immunization Practices (ACIP). MMWR Immunization of Infants, Children, and Adolescents (Part 1), 54(RR-16), 1-2. website, https:/www.cdc.gov/mmwr/preview/mmwrhtml/rr5416a1.htm

Institute of Medicine. (2010). Hepatitis and liver cancer: A national strategy for prevention and control of hepatitis B and C. Washington, DC: The National Academies Press. doi: 10.17226/12793

Hu, D. J., Xing, J., Tohme, R. A., Liao, Y., Pollack, H., Ward, J. W., \& Holmberg, S. D. (2013). Hepatitis $\mathrm{B}$ testing and access to care among racial and ethnic minorities in selected communities across the United States, 2009-2010. Hepatology, 58(3), 856-862. doi: 10.1002/hep. 26286.

Juon, H. S., \& Park, B. J. (2013). Effectiveness of a culturally integrated liver cancer education in improving HBV knowledge among Asian Americans. Preventive Medicine, 56(1), 53-58. doi:10.1016/j.ypmed.2012.11.003

Juon, H. S., Lee, S., Strong, C., Rimal, R.N., Kirk, G. D., \& Bowie J. (2014). Effect of a liver cancer education program on hepatitis B screening among Asian Americans in the Baltimore- 
Washington metropolitan area, 2009-2010. Preventing Chronic Diseases, 11:130258. doi: $10.5888 / \mathrm{pcd} 11.130258$.

Juon, H. S., Rimal, R. N., Klassen, A., \& Lee, S. (2017). Social norm, family communication, and HBV screening among Asian Americans. Journal of Health Communication, 22(12), 981-989. doi:10.1080/10810730.2017.1388454

Kagawa-Singer, M. \& Kho, C. (2015). Asian-American health and disease: an overview. In R. M. Huff, M. V. Kline, \& D. V. Peterson (Eds.), Health promotion in multicultural populations: A handbook for practitioners and students (pp. 292-332). Sage Publications, Inc. doi: 10.4135/9781483368771.n12

Le, M. H., Yeo, Y. H., Cheung, R., Henry, L., Lok, A. S., \& Nguyen, M. H. (2020). Chronic hepatitis B prevalence among foreign-born and U.S.-born adults in the United States, 19992016. Hepatology, 71(2), 431-443. doi:10.1002/hep.30831

Lee, M., Zhu, L., Wang, M. Q., Wei, Z., Tan, Y., Nguyen, M. T., ... \& Ma, G. X. (2017). Psychosocial predictors of HBV screening behavior among Vietnamese Americans. American Journal of Health Behavior, 41(5), 561-570. doi: 10.5993/AJHB.41.5.5

Ma, G. X., Fang, C. Y., Seals, B., Feng, Z., Tan, Y., Siu, P., \& ... Wang, M. (2017). A community-based randomized trial of hepatitis B screening among high-risk Vietnamese Americans. American Journal of Public Health, 107(3), 433-440. doi:10.2105/AJPH.2016.303600

Ma, G. X., Lee, S., Wang, M., Tan, Y., Gao, W., Ma, X., ... \& Toubbeh, J. I. (2011). The role of sociocultural factors in Hepatitis B screening among Asian Americans. Southern Medical Journal, 104(7), 466. doi: 10.1097/SMJ.0b013e31821f8ab0

StataCorp. (2019). Stata Statistical Software. Release 15.1. Stata Corporation, College Station, TX, USA.

Strong, C., Lee, S., Tanaka, M., \& Juon, H. S. (2012). Ethnic differences in prevalence and barriers of HBV screening and vaccination among Asian Americans. Journal of Community Health, 37(5), 1071-1080. doi:10.1007/s10900-012-9541-4

Tanaka, M., Strong, C., Lee, S, \& Juon, H. S. (2013). Influence of information sources on hepatitis B screening behavior and relevant psychosocial factors among Asian immigrants. Journal of Immigrant and Minority Health, 15(4), 779-787. doi: 10.1007/s10903-012-9753-9.

Thompson, C.A., Gomez, S.L., Hastings, K.G., Kapphahn, K., Yu, P., Shariff-Marco, S. \& ... Palaniappan, L.P. (2016). The burden of cancer in Asian Americans: A report of national mortality trends by Asian ethnicity. Cancer Epidemiology, Biomarkers \& Prevention, 25(10), 1371-1382. doi:10.1158/1055-9965.EPI-16-0167

US Department of Health and Human Services Office of HIV/AIDS and Infectious Disease Policy. (2017). National Viral Hepatitis Action Plan 2017-2020. Retrieved from https:/www.hhs.gov/hepatitis/action-plan/national-viral-hepatitis-action-planoverview/index.html

\section{Acknowledgements}

The team would like to thank all volunteers and research staff members who participated and supported this research project in the delivery of a liver cancer educational program. This work was supported by the National Cancer Institute (R25CA129042; R01CA163805). 
Corresponding Author Information

Daisy Le, PhD, MPH/MA

School of Nursing

George Washington University

1919 Pennsylvania Avenue, NW, Suite 500

Washington, DC 20006

Phone: 415-385-7330

Fax: 202-296-1229

daisyle@gwu.edu 